\title{
Survey on Electrical Activity in Earth's Atmosphere
}

\author{
Manoj Kumar Paras ${ }^{1}$ and Pooja Rani ${ }^{2}$ \\ ${ }^{1}$ Department of Physics, Government Degree College, Bhojpur (Moradabad), Uttar Pradesh, India \\ ${ }^{2}$ Department of Applied Sciences, Government Polytechnic Changipur, Noorpur, Bijnor, Uttar Pradesh, India \\ *corresponding author, E-mail: mkparas.iitr@gmail.com
}

\begin{abstract}
Lightning discharge is a spectacular, luminous and one of the most dangerous short lived phenomenon which occurs in the Earth ${ }^{\text {ee }}$ atmosphere ranging from troposphere to the lower ionosphere. Lightning in troposphere is mainly classified as cloud-to-ground (CG) lightning, intra-cloud (IC) lightning and inter-cloud or cloud-to-cloud (CC) lightning discharges. It is assumed that these discharges are caused by the electrically charged thunderclouds. CG lightning has been studied more and is further categorized as positive $\mathrm{CG}$ and negative $\mathrm{CG}$ lightning. Positive $\mathrm{CG}$ lightning is more powerful and accounts only (5-10) percent of the total global lightning and may carry a peak current of $>300 \mathrm{kA}$. An entire family of other electrical discharges also has been reported by the scientific community. They are called "Transient"s Luminous Events (TLE"es)". TLEs occur from top of the thunderclouds up to the lower ionospheric altitudes. Their first visual evidence was documented in 1989. TLE ${ }^{e e}$ are included as blue starters, blue jets, gigantic jets, red sprites, halos, and elves. They are named according to their optical properties, terminal altitudes and different shapes. It has been observed that TLE ${ }^{\text {ee }}$ s are associated with underlying thunderstorm activity and strong tropospheric lightning.

The exact physical mechanism of lightning and TLE ${ }^{e e}$ s and their association with the underlying thunderstorms is still unknown and the research is going on. In this paper, we will study the possible mechanisms of these electrical discharges, their inter-connection and impacts on the atmosphere. This paper is aimed at the readers generally are unfamiliar with the lightning characteristics. We hope that this article will increase the interest among the researchers.
\end{abstract}

\section{Introduction}

Lightning is an electrical breakdown of air and perhaps this is the most spectacular, luminous and highly bright phenomena in the Earthes atmosphere. Benjamin Franklin was the first person who described that thunderclouds contain electricity and this electricity in some situations comes in the form of lightning bolts. For this purpose, he did so many experiments including his most famous experiment of flying kite [1]. He also observed that lightning is attracted by metals. Using this characteristic of lightning, he proposed the lightning rods to save the tall structures from lightning strikes. Lightning is the source of electromagnetic pulses of frequency few $\mathrm{Hz}$ to hundreds of $\mathrm{MHz}$. Lightning is categorized according to their altitude of occurrence. It has been observed that lightning occurs from ground surface up to the ionosphere height (90 $\mathrm{km}$ from ground). The discharges which occur within troposphere region are called low altitude lightning or tropospheric lightning and which occurs from top of the thunderclouds up to the ionosphere are called high altitude lightning or "Transients luminous events (TLEs)". Low altitude lightning includes cloud-toground (CG) lightning, Intra-cloud (IC) lightning, Intercloud or cloud-to-cloud (CC) lightning and cloud-to-air (CA) lightning. IC, CC and CA types of discharges account for about $75 \%$ of global lightning occurrences and do not involve the earth surface [2]. However, CG lightning is more studied as compared to the other lightning discharges because it can be studied using ground based experiments which are easier to do as compared to airborne experiments required to study the other discharges. CG lightning mainly occurs in two ways, either positive charge of the thundercloud lowers to the ground or negative charge lowers to the ground. In first case it is called positive cloud-toground (+CG) lightning and the second case describes the negative cloud-to-ground ( $-\mathrm{CG}$ ) lightning. Sometimes it is also observed that the charges move upwards from tall objects (more than $100 \mathrm{~m}$ ) on the ground and meet to the charge region of opposite polarity in the thunderclouds and produce lightning. It is believed that about $90 \%$ or more of the global downwards discharges are negative $\mathrm{CG}$ and that $10 \%$ or fewer discharges contribute to positive CG lightning [2]. Positive $\mathrm{CG}$ lightning are stronger than negative $\mathrm{CG}$ lightning. They can have the peak current of $300 \mathrm{kA}$ or more. Imager of Sprites and Upper Atmospheric Lightning (ISUAL) observations indicate that the relative frequency of high peak current lightning $(>80 \mathrm{kA})$ is 10 times higher over the oceans than over the land [3]. There are also some bipolar lightning discharges which sequentially transfer to ground both positive and negative charges during the same flash [4]. The temperature of low altitude lightning discharge channel may rise up to $30000 \mathrm{~K}$ with a high pressure of several to tens of the atmospheric pressure [5]. To estimate the various characteristic parameters of lightning, several researchers have produced rockettriggered lightning. Jayakumar et al. [6] measured the electric fields in the immediate vicinity $(0.1$ to $1.6 \mathrm{~m})$ of the rocket triggered lightning channel. Using the electric fields and its associated currents in the channel, the mean input energy for return strokes in the triggered lightning over the first $50 \mu \mathrm{s}$ was computed and found $10^{3}-10^{4} \mathrm{~J} \mathrm{~m}^{-1}$. The values of mean channel radius and resistance per unit channel length at the instant of peak power (which occurred at around $0.4 \mu \mathrm{s}$ ) were estimated $0.32 \mathrm{~cm}$ and $7.5 \Omega \mathrm{m}^{-1}$ respectively. After studying eight strokes of rocket-triggered 
lightning, they calculated the mean values of peak power and energy $9.6 \times 10^{8} \mathrm{~W} \mathrm{~m}^{-1}$ and $3.6 \times 10^{3} \mathrm{~J} \mathrm{~m}^{-1}$, respectively. Recently, positrons the anti-particles of electrons (particle having same mass as of electron but opposite charge) have been observed in the Earth ${ }^{\text {ee }}$ s atmosphere through ground based experiment which was created by lightning through photonuclear reactions [7]. In order to explain this they described that thunderclouds and growing discharges produce strong electric fields which generate avalanches of relativistic runaway electrons and these electrons emit highly energetic radiation called $\gamma$-rays through bremsstrahlung process. In this process, the electromagnetic radiations are produced by the deceleration of charged particles by other charged particles. These $\gamma$-rays have been detected by ground based experiments [8] and airborne detectors [9] and as terrestrial $\gamma$-ray flashes [10]. The gamma rays knock neutrons out of the nucleus of nitrogen atoms in the atmosphere. The nitrogen atoms that have lost their neutrons become unstable and break down, releasing positrons into the air. Positrons are the antimatter equivalent of electrons, and when the two of them touch they annihilate each other. These annihilation events produce the extended gamma ray bursts. A comparative study of light intensity and current of lightning channel was done by Wang et al. [11]. It is found that the current and light signals at the bottom of the lightning channel exhibit a linear relationship during the entire rising stage, up to the peak value. During several microseconds after the current and light peaks, the light intensity usually decreases faster than the current. Later, this trend is reversed and, in some cases, the light signal shows another rising trend even as the current keeps decreasing. A complete theory behind the behaviors of lightning channele s luminosity and current is still not clear. There are so many other characteristics of lightning which are yet to be studied.

Another form of discharges called high altitude lightning or transient luminous events (TLEs) has also been observed during more than two decades [12,13]. Although eyewitness reports of TLEs have been recorded for more than a century, the first image of one was captured only in 1989, serendipitously during a test of a low-light television camera. Since then, several different types of TLEs above thunderclouds have been documented and classified. They can be observed from thundercloud tops up to the ionosphere in different shapes and colors. They seem to be fairly common in most regions of the globe, appearing over North, Central and South America, Europe, Australia, Japan China and India. High altitude lightning are included red sprites, blue jets, blue starters, elves, sprite halos, gigantic jets etc. MacKenzie and Toynbee [14] reported for the first time visual observation of brief flash of light above thunderstorm but it was ignored due to the lack of sufficient evidences. It was also predicted earlier in 1925 by Charles Thomson Rees Wilson about these discharges that the electric field caused by low altitude lightning can cause ionization at great heights and could therefore give rise to discharges between clouds and the upper atmosphere, but the direct visual evidence was documented in 1989. Later, the first ground based experimental observation was reported by Franz et al. [15]. The global occurrence rate of all TLEs is $\sim 40$ events per minute, or 57,000 TLE events per day. According to Kuo et al. [16], the analysis of 1415 TLEs collected by the ISUAL instrument indicates that sprites, halos, and elves have spatially averaged brightness $1.5,0.3$, and 0.17 Mega Rayleigh and the energy deposition 22, 14, and $19 \mathrm{MJ}$ per event, respectively. They found the global energy deposition rates in the upper atmosphere are 22, 14 and $665 \mathrm{MJ} \mathrm{min}^{-1}$ from sprites, halos and elves respectively. In the next sections, we will study the mechanism of tropospheric lightning especially CG lightning discharge and the association of thunderstorms with the upper atmosphere.

\section{Tropospheric Lightning and its Mechanism}

It is well known that lightning is the spontaneous momentary high-current electrostatic discharge, which is initiated in the thunderclouds and the path usually stretch over kilometers in length [1]. It is necessary to understand the charging of thunderclouds before the mechanism of lightning discharge. Thunderclouds contain ice particles, as these ice particles grow, interact and collide with each other they get charged [17]. The larger ice particles acquire negative charge and smaller one get positive charge. Now due to updrafts, downdrafts and gravity the positive ice particles and negative ice particles tend to separate. Being smaller in size, positive charge particles tend to move upwards and heavier charged particles drift downwards under gravity. However, the exact reason of the charge separation is under investigation [18]. The separation of charge occurs until upper portion of the cloud becomes net positively charged and lower portion becomes net negatively charged. The charge-separation produces high potential difference within the thundercloud or between the cloud and ground. The potential difference can reach up to several tens of millions of volts. As soon as the potential difference reaches beyond the dielectric strength of air $\left(25 \mathrm{kV} \mathrm{cm}^{-1}\right.$ at ground surface) a flash called return stroke is produced and all the thundercloud charge gets neutralized with the release of enormous amount of energy. However the initiation of lightning is under debate till date. More recently, Chilingarian et al., [19] observed that the negative CG lightning is initiated by Relativistic Runaway Electrons Avalanches (RREA) within the region of thundercloud electric field. According to them RREA can provide enough ionization to play a significant role in the unleashing of the lightning flash. The depiction of various types of tropospheric lightning discharges is shown in Fig. 1. Positive and negative CG lightning begins with an invisible discharge called stepped leader [1]. In +CG lightning, stepped leader carries the positive charge from top of the thundercloud towards ground and ionizes the path through which it propagates. Exactly how the positive stepped leader works is not understood but it is known that it moves from cloud to ground in rapid steps ranging from 5-20 m long with a downward velocity of $10^{6} \mathrm{~m} \mathrm{~s}^{-1}$ [20]. Positive leaders generally are non-ramified and seem to follow a single trajectory [21]. Each leader step occurs in less than a millionth of a second. The time between steps is about 50 millionths of a second. Positive charge is continuously 
lowered from the positive charge region of the thundercloud into the leader channel. The total time taken by the stepped leader to travel from the main positive charge center of the thundercloud to the ground is around 10-20 ms. When the stepped leader is near ground, its relatively large positive charge induces large amounts of negative charge on the earth beneath it and especially on objects projecting above the earth "s surface. Since opposite charges attract each other, the large negative charge on earth attempts to join the large positive charge within the leader. As soon as the positive stepped leader reaches near the ground a negative streamer appears from the ground and approaches to meet it. When two make contact visible lightning called return stroke instantaneous propagates upwards with a velocity of around one-third of the velocity of light from the ground along the path created by the positive leader. In this way, the return stroke neutralizes all the positive charge distributed in the stepped leader.

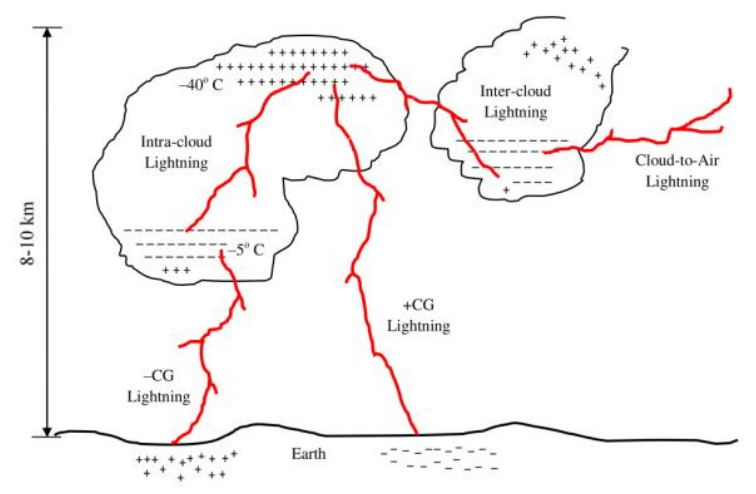

Fig. 1. Depiction of various forms of tropospheric lightning discharges.

Positive CG lightning flashes usually occur in a single return stroke and tend to be followed by a continuing current that lasts for tens to hundreds of milliseconds [22, 23]. Nag et al. [24] reported that out of the 52 positive flashes $42(81 \%)$ were single-stroke, $9(17 \%)$ two-stroke, and $1(2 \%)$ threestroke flashes. Return stroke is typically very bright and intense. The peak values of currents in return strokes may reach $>300 \mathrm{kA}$ [25]. If some amount of charge remains in the cloud after first stroke the other leader namely dart leader travels down without stepping or branching through the existing main channel. Dart leader propagates with a velocity of $0.1 \times 10^{7}-2.3 \times 10^{7} \mathrm{~m} \mathrm{~s}^{-1}$ and takes around $1 \mathrm{~ms}$ of time to approach the ground [26]. When the dart leader nears the ground another stroke called subsequent return stroke appears from the ground and travels back up the channel to the thundercloud. This process of dart leader and subsequent return stroke goes until all the thundercloud positive charge gets neutralized. The peak values of currents in subsequent return strokes of $+\mathrm{CG}$ lightning may ranges from 90-140 kA [27]. The complete mechanism of $+\mathrm{CG}$ lightning is shown in Fig. 2. Thus, lightning is an electrical discharge between the positive and negative charges. When the charge centers are within the cloud it is called Intra-cloud lightning. If the discharge takes place between the negative charge centre of the cloud and positive charge center at the ground then it is called negative $C G$ lightning. Negative $C G$ lightning has been studied widely as compared to $+\mathrm{CG}$ lightning. In negative CG lightning, the stepped leader is highly branched and a lightning flash consists of more than two strokes [1]. Saba et al. [28] observed the properties of -CG lightning using high speed video recordings. According to them the average number of strokes per flash was 3.8. Numerous researchers have been observed that strong $+\mathrm{CG}$ lightning discharges are associated with red sprites a member of the family of TLEs.

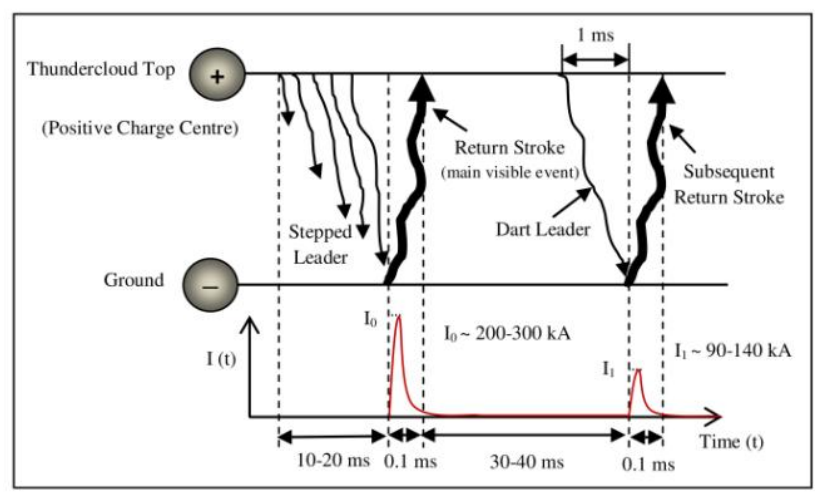

Fig. 2. Mechanism of positive cloud-to-ground lightning discharge.

\section{High Altitude Lightning Discharges}

The family of high altitude lightning or TLEs includes red sprites, blue starters, blue jets, gigantic jets, halos and elves. TLEs are under investigation till date. Several groups across the world are working on them through ground based, airborne and space based experiments and also theoretically. In this section, we will study the various properties and possible mechanism of these discharges.

\subsection{Red Sprites}

Red sprites are optical flashes and span the full vertical extent of the atmosphere, from above thundercloud tops to the lower ionosphere [12]. Perhaps, these are the most studied among TLEs and found to be associated with + CG lightning. The life time of these events is from a few to tens of ms. Sometime red sprites have been observed for quite longer duration i.e. $283 \mathrm{~ms}$ [29]. This may be associated with long lasting continuing currents in the causative $+\mathrm{CG}$ lightning. Red sprites initiate at an altitude of around $90 \mathrm{~km}$ and terminate at around $40 \mathrm{~km}$ from ground surface. According to Sentman et al. [30], the brightest region the "head" lies within the bracketed range of altitudes $66-74 \mathrm{~km}$ $( \pm 4 \mathrm{~km})$. Above the head there is often a faint red glow or wispy structure (,haire) separated from the bright head by a dark band ("hairline"), and extending to $88 \pm 5 \mathrm{~km}$. Further they reported that on some of the bright sprites there is a dark band ("collar") beneath the head at $66 \pm 4 \mathrm{~km}$, below which extends tendril-like filamentary forms. The color of the tendrils is red just below the collar, gradually merging 
into blue with distance downward. The blue colored tendrils was found to reach as low as $40 \mathrm{~km}$. Sprites rarely occur singly, they usually occur in clusters of two, three or more [31]. Based on the structures, sprites are classified as Column, Carrot, Jelly fish and Angel types [32]. Using high speed camera, it has been observed that sprites are initiated with the formation of streamers. The sprite streamers propagate with high speed $\left(10^{6}-10^{7} \mathrm{~m} \mathrm{~s}^{-1}\right)$ at higher altitudes and slow down when reach at lower altitudes [33]. Sprite streamers can propagate downward as well as upwards from their origination point [34]. It was found that streamer which moves downwards was associated with column sprite and which move upwards was associated with carrot sprite. During the journey of sprite streamers, their both positive and negative accelerations were observed in a range of $10^{5}$ $10^{10} \mathrm{~m} \mathrm{~s}^{-2}$ [33]. The lateral dimension of a unit sprite is typically $5-10 \mathrm{~km}$, corresponding to a volume more than $10^{3}-\mathrm{km}^{3}$. According to latest observation [35], the average base altitude, terminal altitude and diameter of each column of columniform sprites are $72.4 \pm 2.4,82.3 \pm 1.8$, and $<0.5$ $\mathrm{km}$, respectively. The mean brightness of the unit sprites by taking average over the outer dimmer portions is 10-50 kiloRayleigh [12]. Red sprites usually occur above the anvils of large mesoscale convective systems and are associated with strong +CG lightning flashes with large peak current $(>120$ $\mathrm{kA}$ ), and rarely with negative cloud-to-ground lightning $[36,37]$. Sprites observed over the oceans are brighter as compared to seen over land. Red sprites are produced after $\sim 1-10 \mathrm{~ms}$ of the causative lightning discharge. The sprite discharge enhances the local conductivity appreciably and allows the current to flow within it over a height interval of, say 25-30 km. Cummer et al. [38] observed three events of sprites and found the peak vertical current flowing in the sprite body was around $3.3 \mathrm{kA}, 3.3 \mathrm{kA}$ and $1.6 \mathrm{kA}$. Based on the duration of these currents, they reported the total ionospheric charge transfer for these three events is $5 \mathrm{C}, 6 \mathrm{C}$, and $42 \mathrm{C}$ respectively. Further, they suggested that the intense current flowing in the body of sprites is a source of extremely low frequency (ELF). The fast heating and expansion of air in the sprites leads to emission of infrasonic acoustic waves which were observed on the ground [39]. It is observed that parent lightning charge moment change play important role for the initiation of sprites. The charge moment change $\Delta \mathrm{M}_{\mathrm{q}}(\mathrm{t})=\mathrm{Z}_{\mathrm{q}} \times \mathrm{Q}(\mathrm{t})$ is defined as the product of $\mathrm{Z}_{\mathrm{q}}(\mathrm{km})$, the mean altitude above ground level from which the charge is lowered to ground, and $\mathrm{Q}(\mathrm{t})$, the amount of charge lowered. Hu et al. [40] analyzed a large number of sprite-associated lightning discharges and found that at least $120 \mathrm{C} \mathrm{km}$ parent lightning charge moment is required for the initiation of sprites. Further, they reported that the probability of sprite generation for positive lightning with $>1000 \mathrm{C} \mathrm{km}$ charge moment change in $<6 \mathrm{~ms}$ is $>90 \%$, while the sprite probability for lightning with $<600 \mathrm{C} \mathrm{km}$ charge moment change in $<6 \mathrm{~ms}$ is $<10 \%$. It is important to note the difference between sprite producing and non sprite producing lightning discharges. Sprite producing lightning radiates more strongly at lower frequencies than more typical lightning discharges i.e. sprite producing lightning discharge must have a longer duration and transfers more charge from the thundercloud to the ground as compared to non sprite producing lightning [41]. Sprite spectra were studied by Hampton et al. [42] and theoretical spectra were computed by Milikh et al. [43]. They are found strong in the first positive band of nitrogen (red) at higher altitudes and in the $\mathrm{N}_{2}{ }^{+}$first negative band and in the second positive band of nitrogen (blue) at lower altitudes.

Pasko et al. [44] described that red sprites are produced due to the heating and ionization of the upper atmosphere due to the thundercloud electric field. Bell et al. [45] suggested by his simulation work that runaway electrons play an important role in the production of optical emissions such as red sprites. Further, they described that this is possible only when a large amount of quasi-electrostatic (QE) field is produced in the upper atmosphere. The large QE field is generated by strong positive CG lightning which should lower more than $250 \mathrm{C}$ of charge from an altitude of at least $10 \mathrm{~km}$. Yukhimuk et al. [46] numerically calculated the intensity and spectra of optical emissions from red sprites produced as a result of runaway air breakdown in the upper atmosphere. The computed optical characteristics of red sprites, such as intensity and duration of optical emissions, altitude, and shape of the emission region, were in agreement with observations. Other mechanisms, such as conventional breakdown of the air as a result of quasielectrostatic field changes [44], predict the minimum altitude for visible emissions to be about $60 \mathrm{~km}$. However, red sprites also have been observed at altitudes of $\sim 35 \mathrm{~km}$ or even lower [30]. In conclusion, we can say that red sprites are associated with combined effects of QE heating and runaway breakdown process.

\section{Mechanism of Red Sprites}

There are two mechanisms behind the occurrence of red sprites. One is Quasi-Electrostatic heating and other is runaway breakdown. The first one is dominant at higher altitudes and second describes the various optical properties of these emissions at lower altitudes. Both the models are presented below.

Quasi-Electrostatic Heating: It was predicted theoretically by C. T. R. Wilson in 1925 [47] that there should be some electric discharges at higher altitudes. He recognized that the thundercloud electric field $\mathrm{E}$ which decreases with altitude ( $r$ ) as $1 / r^{3}$ and the critical breakdown electric field of atmosphere $E_{k}$ falls more rapidly as $\exp \left(-r / \mathrm{r}_{0}\right)$. This relationship of $\mathrm{E}$ and $\mathrm{E}_{\mathrm{k}}$ with altitude $r$ leads to the result that there will be a height above which the electric field due to the thundercloud $\mathrm{E}$ exceeds the atmospheric breakdown electric field $E_{k}$ and outcome will be an electric discharge (Fig. 3). Later, these discharges were named red sprites. According to Pasko et al. [48], as the thundercloud electric charges slowly build up before a lightning discharge, high altitude regions are shielded from the quasi-electrostatic fields of the thundercloud charges by space charge induced in the conducting atmosphere at lower altitudes. When positive charge of the thundercloud is removed by $+\mathrm{CG}$ lightning the remaining charges of opposite sign in and above the thundercloud produce a large quasi-electrostatic field $\mathrm{E}$ that appears at all altitudes and endures for the time 
$\sigma / \varepsilon_{0}$, which is called local relaxation time. Where, $\varepsilon_{0}$ is the dielectric permittivity of free space and $\sigma$ is the local atmospheric conductivity in the presence of electric field.

Using a simple dipole model with cloud charge Q left at altitude $\mathrm{z}$ above a perfectly conducting ground, which forms an image charge located at a depth $\mathrm{z}$ beneath the ground, Raizer et al. [49] obtained the following expression for the resulting Quasi-electrostatic field E as a function of altitude $h$ given by

$$
\mathrm{E}=\frac{\mathrm{zQ}}{\pi \varepsilon_{0} h^{3}}\left[1+\left(\frac{h}{2 \mathrm{~h}_{\mathrm{i}}-h}\right)^{3}\right]
$$

where, $\mathrm{h}_{\mathrm{i}}=80 \mathrm{~km}$ is the height of the ionosphere.

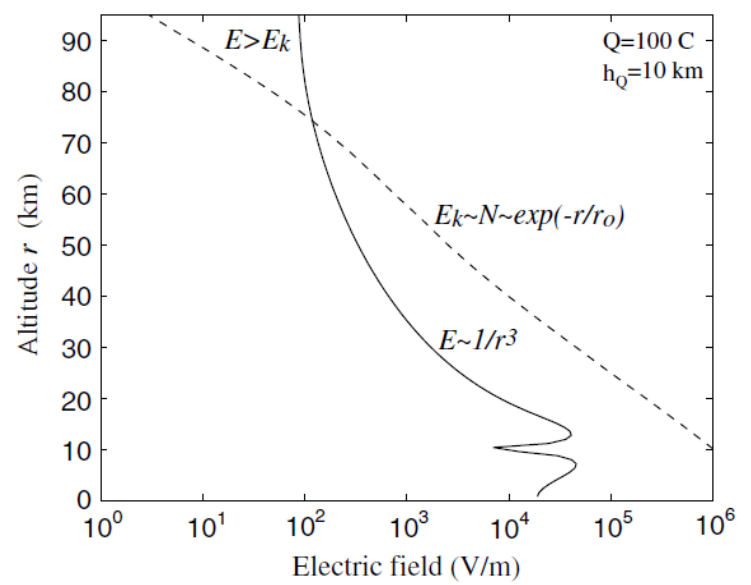

Fig. 3. Physical mechanism of red sprites. At higher altitudes the lightning driven electric field (E) exceeds the dielectric strength of air i.e. conventional breakdown electric field $\left(E_{k}\right)$ results in discharges named red sprites [50]. In this Fig. Q is the thundercloud charge and $\mathrm{h}_{\mathrm{Q}}$ is the height from which $\mathrm{Q}$ is removed by the causative $+\mathrm{CG}$ lightning.

This temporary existing electric field leads to the heating and ionization in higher altitudes and produce optical emissions called red sprites. This mechanism is shown in Fig. 4.

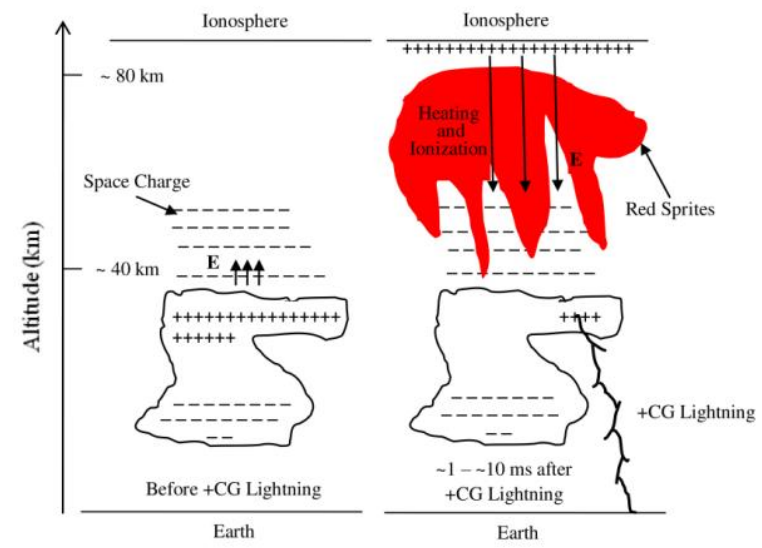

Fig. 4. Schematic of red sprites. Large Quasi-electrostatic field produces heating and ionization in higher altitudes resulting in red sprites. The figure is partly adopted from Pasko et al. [48]
Runaway Breakdown Mechanism: The phenomenon of Runaway Breakdown (RB) was predicted in 1992 by Gurevich, together with Gennady Milikh and Robert Roussel-Dupre [51]. This phenomenon has its origins in the interaction of fast particles with matter. The braking force $\mathrm{F}$ acting on an energetic particle in matter is determined by the ionization losses [52]. It has been seen that the $\mathrm{F}$ decreases with increase in electron energy $\varepsilon\left(\sim 10^{2}-10^{6} \mathrm{eV}\right)$ in nonrelativistic region [53]. The decrease in the ionization braking force becomes weaker owing to relativistic effects. For $\varepsilon \sim 1 \mathrm{MeV}, \mathrm{F}$ reaches its minimum $\mathrm{F}_{\text {min }}$, and then a logarithmically slow increase begins. Fast particles (cosmic ray electrons) with energy $\varepsilon>\varepsilon_{\mathrm{c}}$ present in the atmosphere are accelerated in the presence of large ambient thundercloud electric field $\mathrm{E}$ given in $\mathrm{eq}^{\mathrm{n}} 1$.

The $\varepsilon_{\mathrm{c}}$ is given by [54]

$$
\varepsilon_{c}=\frac{m_{e} c^{2} E_{c}}{2 E}
$$

where, $\quad E_{c}=2.16 \exp \left(-h / h_{0}\right) \mathrm{kV} / \mathrm{cm}$

$\mathrm{m}_{\mathrm{e}}=$ mass of electron, $\mathrm{c}=$ speed of light, and $h_{0} \approx 8-10 \mathrm{~km}$

It is important that the value of the runaway breakdown threshold electric field $E_{c}$ is one order of magnitude smaller than the conventional breakdown electric field $E_{k}$. These fast particles gain enormous amount of energy in the presence of $\mathrm{E}$ and become runaway electrons. An electron becomes runaway when it is placed in an electric field which creates a large enough force on it to overcome the drag forces caused by the interactions of the electron with the medium. Runaway electrons collide with the other atmospheric molecules, ionize them and produce large amount of secondary low energy electrons. Although many of the secondary electrons have low energy, some of the electrons may have energy greater than the threshold energy, that is $\varepsilon>\varepsilon_{\mathrm{c}}$. The electric field $\mathrm{E}$ will accelerate these energetic electrons, so that they also become the runaway electrons, which in turn results in additional ionization of air and the generation of other runaway electrons. As a result an exponentially increasing avalanche of runaway electrons along with a great deal of low energy secondary electrons are produced, eventually it brings the breakdown of air in the form of red sprites. The experimental verification of this mechanism is not possible to do in laboratory because of the large dimensions are required to develop avalanche of electrons (tens to hundreds of meters at sea level). Since, this theory is founded on the well known physical principles so it strongly favors of its existence. In addition, the largescale lengths and electric fields associated with thunderstorms provide ideal conditions for development of runaway breakdown.

\subsection{Blue Starters, Blue Jets and Gigantic Jets}

Blue starters and blue jets were observed first time on July 1, 1994 by the scientists of University of Alaska [55]. Fifty nine examples of luminous columns propagating from cloud tops during 22 minute period were recorded. These were found different from sprites in some aspects. Due to the upward motion and the blue color of the phenomena, they 
were given the name blue starters/blue jets. Blue starters are slow moving fountains of blue light emanating from the cloud top and reaching up to $\sim 21 \mathrm{~km}$ altitude [56,57]. The velocity of blue starter varies over its life span, from $\sim 27$ $\mathrm{km} \mathrm{s}^{-1}$ to $\sim 180 \mathrm{~km} \mathrm{~s}^{-1}$ [57]. Blue starters play the role in transferring energy from troposphere to the stratosphere.

Blue jets are extended version of blue starter and may continue up to $\sim 50 \mathrm{~km}$ altitude. Blue jets develop upward in conical shape with conical angle $14 \pm 7.5^{\circ}$ at a speed of $\sim 100$ $140 \mathrm{~km} \mathrm{~s}^{-1}$, having a life time of $\sim 200-300 \mathrm{~ms}$ [55]. The first published theoretical models suggested that they are either gigantic positive streamers or negative streamers or a beam of runaway electrons. Pasko and George [58] based on their three dimensional fractal model described that blue jets and blue starters can be formed by a fast $(\sim 1 \mathrm{~s})$ accumulation of $\sim 110-150$ C of positive thundercloud charge distributed in a volume with effective radius $\sim 3 \mathrm{~km}$ near the cloud top at $15 \mathrm{~km}$. Their model results also indicate that the dominant contributors of the observed blue emissions are second positive band of $\mathrm{N}_{2}$ and first negative band of $\mathrm{N}_{2}{ }^{+}$. The blue jets do not occur in association with either positive or negative CG lightning as reported by the National Lightning Detection Network. Observations suggest that blue jets show association with high negative cloud-to-ground flash rates (not with any individual flash) and large hail [59].

Gigantic Jets (GJs) are electric discharges which shoot upwards with a velocity of $10^{6}-10^{7} \mathrm{~m} \mathrm{~s}^{-1}$ from thunderstorm cloud tops in the atmosphere and can reach altitudes above $80 \mathrm{~km}$. These are the long lasting TLEs (up to $800 \mathrm{~ms}$ ) and were first reported in 2002 over Caribbean Sea [60]. They are the most rarely observed TLEs as compared to elves, halos and red sprites [3]. GJs bridge the gap between thunderclouds and ionosphere and thus play an important role in global electric circuit. Soula et al. [61] observed that the CG lightning activity was ceased a few tens of seconds before the evolution of gigantic jets and they originate mainly as intra-cloud discharges without any charge transfer to Earth. GJs are developed in the form of streamers both negative as well as positive [62]. Negative polarity gigantic jets transfer negative charge from cloud tops to the ionosphere and vice-versa. Remote-sensing of VLF emissions have revealed that most GJs are of negative polarity and transport hundreds of coulombs of negative charge to the ionosphere [63]. GJs may involve charge moment changes as low as 1000-2000 C km [64] and as high as $\sim 12000 \mathrm{C} \mathrm{km}[63,65]$ and may originate either from a tall cloud top or a winter thunderstorm of only $\sim 6.5 \mathrm{~km}$ tall. The negative polarity GJs are more energetic as compared to positive GJs. GJs emit extremely low frequency (ELF) and were not triggered by any CG lightning activity. Milikh et al. [66], through their theoretical calculations showed that a leader can become blue starter, blue jet, or gigantic blue jet. It is based on the amount of current it carries. A leader becomes a blue starter when it carries a current $\mathrm{I}<100 \mathrm{~A}$ and terminates at an altitude of $25 \mathrm{~km}$ only. Fully developed blue jets have the stoppage height between 25 and $40 \mathrm{~km}$, which corresponds to $110 \mathrm{~A}<\mathrm{I}<1000 \mathrm{~A}$ carried by the leader. When the leader carries a current I more than $1000 \mathrm{~A}$ it goes above $40 \mathrm{~km}$ and its streamers fly to the ionosphere making it a gigantic blue jet. Blue jets are either negative streamers [67] or positive streamers [68]. A negative streamer propagates due to ejection of electrons from its head however a positive streamer requires a population of ambient electrons for its development. A detailed modeling of mechanism of blue jets was done by Raizer et al. [69] by assuming the blue jet as a combination of leader and streamer.

\subsection{Elves}

Elves (Emissions of Light and VLF perturbations due to EMP Sources) are short duration $(<1 \mathrm{~ms})$ luminous events of 200-500 km size expanding outwards and observed at the bottom edge (80-95 $\mathrm{km}$ altitude) of the ionosphere either in the form of donut shape with dark central region [70] or pancake shape (flat disc shape) with a luminous central part [71]. Elves occur above thunderstorms, both in conjunction with sprites and alone. They are predominantly red in color. The typical vertical thickness of elves is several $\mathrm{km}$, and the horizontal extent as much as $\sim 700 \mathrm{~km}$ [72]. Elves are observed above both positive and negative CG lightning. It is observed that most of the elves $(78 \%)$ are associated with negative CG lightning [73]. Chen et al. [3] reported 5434 elves, 633 sprites, 657 halos and 13 gigantic jets based on the ISUAL experiment from July 2004 to June 2007. Based on this experiment, they found global rates of $3.23,0.50$, 0.39 , and 0.01 events per minute for elves, sprites, halos, and gigantic jets, respectively. Their observations clearly indicate that the elves are the most dominant among TLEs. They also observed that the occurrence rate of elves increases rapidly when sea surface temperature exceeds $26^{\circ}$ C. It seems that the warm surface of ocean provide some sort of heat energy to produce intense oceanic lightning responsible for elves. In the ISUAL survey, elves concentrate over the Caribbean Sea, South China Sea, East Indian Ocean, central Pacific Ocean, West Atlantic Ocean, and southwest Pacific Ocean [3]. ISUAL observations also indicate that the frequency of Elves is more over the ocean as compared to land. Elves can enhance the ionospheric free electron density globally as well as locally. VLF remote sensing of ionization produced by elves indicates electron density enhancements of $460 \mathrm{~cm}^{-3}$ averaged over $220 \mathrm{~km}$ radius and $10 \mathrm{~km}$ high region [74]. Further, According to a calculation by Chen et al. [3], the fractional global increase in total number of free electrons due to elves at the height of $80-90 \mathrm{~km}$ is $1 \%$ and locally it came around $5 \%$. The electromagnetic waves generated by lightning discharges (sferics) associated with elves have a stronger VLF component around $7 \mathrm{kHz}$ than normal CG sferics.

The electromagnetic coupling of troposphere and lower ionosphere by lightning induced intense electromagnetic pulses (EMPs) which cause heating, ionization and optical emission at altitude of $75-105 \mathrm{~km}$ and results in the form of elves was predicted by Inan et al. [75] and Taranenko et al. [76]. EMPs produced by strong CG lightning return strokes with peak current $\mathrm{I}_{\mathrm{p}}>80 \mathrm{kA}$ produce bright $\left(>10^{7}\right.$ Rayleigh) optical flashes and significant ionization changes at an altitude of $80-95 \mathrm{~km}$ [77]. According to their computersimulation work, the emission of first positive band of $\mathrm{N}_{2}$ 
produced by EMPs expands $(\sim 30 \mathrm{~km}$ thin $)$ to radial distances up to $250 \mathrm{~km}$ at very high apparent speed in a short time of $300-500 \mu \mathrm{s}$ in the form of elves. In times of $>1-\mathrm{ms}$ the optical emission appears as a thin layer of lateral extent of $\sim 300-400 \mathrm{~km}$. Barrington-Leigh et al. [78] modeled a homogeneous EMP from the return stroke/vertical portion of the lightning interacting with a homogeneous atmosphere, which resulted in unstructured emissions (elves) for $1 \mathrm{~ms}$. According to Hobara et al. [79], sprites tend to associate with a large ionospheric disturbances with a large charge transfer (52-175 C), whereas a large lightning peak current (223-470 kA) (or slow-tail amplitude) leading to the strong EMPs is necessary to initiate elves, but with rather small ionospheric disturbances. Hence, unanimously it can be inferred that the nitrogen molecules in lower $\mathrm{D}$ region of ionosphere are excited by the impact of ambient electrons heated by EMPs from energy $0.03 \mathrm{eV}$ to $>7 \mathrm{eV}$ and than de-excited in the form of optical emissions called elves. A schematic of an elve event is shown in Fig. 5. The time difference between the initiation of elves and the causative return stroke is 300- $\mu$ s. Lightning and TLEs are shown in Fig. 6.

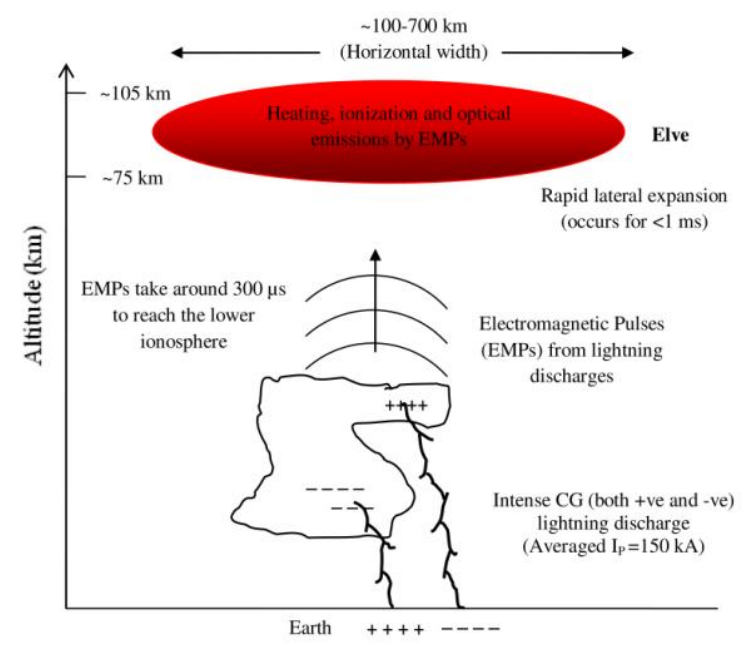

Fig. 5. Mechanism of Elves. Elves are produced by electromagnetic pulses from strong CG lightning return strokes. This figure is partly adapted from Rodger [80]

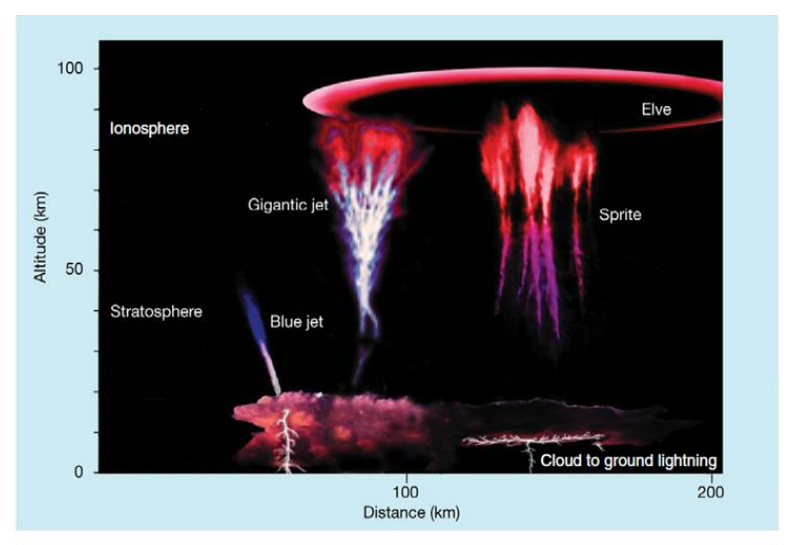

Fig. 6. Depiction of low altitude lightning and TLEs [81]

\subsection{Halos}

Halos, sometimes also referred as sprite halos are short lived (1-2 ms) diffused luminous events having lateral extent 40$70 \mathrm{~km}$ and usually are observed in the altitude range 75-85$\mathrm{km}$ [70]. They are associated with both $+\mathrm{CG}$ lightning as well as -CG lightning [82,83]. Halos are much dimmer than sprites. Their brightness is similar to an average sprite (5001000 kilo Rayleigh) and is red in color. Their brightness depends on the peak current and polarity of causative lightning. Halos associated with positive lightning are brighter than halos associated with negative lightning. Frey et al. [83] observed that the frequency of occurrence of halos is more over the open ocean rather than over the land surfaces and they mostly are associated with -CG lightning. They are initiated typically after 1 or $2 \mathrm{~ms}$ after the causative lightning return stroke. Halos tend to be much smaller (maximum diameter $100 \mathrm{~km}$ ) and lower $(80-65 \mathrm{~km})$ than elves. Sprites often initiate from the underside of the descending halo feature, but no sprite is found associated with -CG lightning generated halo. Like elves, halos tend to be centered more or less directly over the parent $\mathrm{CG}$ lightning discharge. Frey et al. [83] showed that $50 \%$ of the halos are unexpectedly associated with -CG lightning while nearly $99 \%$ of the sprites are induced by $+\mathrm{CG}$ lightning. It is found that the quasi-electrostatic field in the bright halo region is higher than the conventional breakdown electric field $E_{k}$ and it relaxes with a faster rate as compared to surrounding region due to the enhanced conductivity of halo region by ionization process [16]. The recorded electric field related to this halo event was produced by a lightning discharge that had a total charge moment change of -1450 $\mathrm{C}-\mathrm{km}$. In this halo event, the total number of photons of first positive band of $\mathrm{N}_{2}$, second positive band of $\mathrm{N}_{2}$, and first negative band of $\mathrm{N}_{2}^{+}$emissions were found to be $4.6 \times 10^{23}$, $4.3 \times 10^{22}$, and $1.6 \times 10^{21}$ photons, respectively. It is widely accepted that both the sprite steamers and halos are driven by CG lightning induced quasi-electrostatic fields i.e. quasielectrostatic field heat the neutral middle atmosphere $(\sim 75$ $\mathrm{km})$ and produces ionization and optical emissions in the form of halos $[48,78,84]$.

\section{Impact of Lightning and TLEs on the Atmosphere}

Lightning plays an important role in the production of nitrogen oxides $\mathrm{NO}_{\mathrm{x}}$ (nitric oxide $\mathrm{NO}$ and nitrogen dioxide $\left.\mathrm{NO}_{2}\right)$ [85]. $\mathrm{No}_{\mathrm{x}}$ controls the concentration of ozone gas $\left(\mathrm{O}_{3}\right)$ which is a green house gas. Thus, excessive lightning may influence the atmospheric chemistry as well as climate change. With global warming it is expected that the frequency of lightning discharges will increase around 50\% over this century [86]. Strong lightning activity can ignite forest fires in temperate and boreal forests which are associated with the emission of greenhouse gasses and may again contribute to global warming. TLEs like blue jets, gigantic jets and red sprites also produce $\mathrm{NO}_{\mathrm{x}}$ in the middle atmosphere but their global impact is low [87]. However, their local production of $\mathrm{NO}_{\mathrm{x}}$ is significant. Lightning and possibly red sprites and gigantic jets play an important role 
in the global atmospheric circuit. It is well known that lightning generated extremely low frequency (ELF) contributes to the natural phenomena called Schumann Resonances [88]. Schumann Resonances are a set of spectrum peaks in ELF ( $8 \mathrm{~Hz}, 14 \mathrm{~Hz}, 20 \mathrm{~Hz}$ and so on) portion of the Earthes electromagnetic field spectrum and variations in them corresponds to changes in solar activity, Earth "s magnetic environment, water aerosols in atmosphere and other Earth-bound phenomena. Recently many researchers have been observed that TLEs also emit radiations in the ELF band. These ELF radiations propagate in Earth-ionosphere waveguide and should contribute to Schumann Resonances [89]. Recently, Shklyar [90] calculated that the lightning triggered plasma waves in Earth ${ }^{\text {ee }}$ magnetosphere absorb energy from slow particle and energize electrons to level that can damage satellites severely. It also has been observed that tropospheric lightning and thunderstorms are the source of powerful bursts of $\gamma$-rays of short duration (tens of $\mu$ s to few of ms) and energy ranging from few $\mathrm{MeV}$ to several tens of $\mathrm{MeV}$ called Terrestrial Gamma ray Flashes (TGFs) [91,92,93]. It seems that TGFs are the incredibly bright and most energetic phenomenon naturally occurring in Earthes atmosphere and they can be dangerous for airplanes and aircraft transports, both for the crew and the on board electronics. Similar phenomena associated with lightning activity called gammaray glows endure for seconds to tens of minutes have been also observed in the troposphere more common near the top of the thunderstorms which are less bright as compared to TGFs [94].

\section{Discussions and Conclusions}

Association of electrical activity in thunderstorms to various types of optical emissions called TLEs provides the direct evidence of coupling from the lower atmosphere to upper atmosphere. The previous experimental observations [33,95] have revealed that the sprite structure is very close to streamer like discharges. The streamers propagate with acceleration and expansion in the quasi-electrostatic fields generated by strong $+\mathrm{CG}$ lightning. Perhaps, among the TLEs sprites are most studied both experimentally as well as theoretically but no concrete theory has been established which can explain all of its features clearly. The occurrence rate of gigantic blue jets is small as compared to the occurrence rate of sprites, halos and elves [3]. Therefore, knowledge of jets and their associated thunderclouds is very limited due to the very limited cases but it seems that jetes typical size, velocity and other parameters can be very sensitive to the initial conditions at the top of thunderclouds such as the charge distribution and rate of charge accumulation. Gigantic jets transfers a large quantity of charge (tens to hundreds of Coulomb) from thundercloud tops to the ionosphere and radiates in extremely low frequency. Since most of the gigantic jets were observed of negative polarity which leads a direct effect on the ionosphere by discharging some of its charge and thus reduce its potential [64]. In the conventional picture, the main components of Earth's global electric circuit are thunderstorms, the conducting ionosphere, the downward fair-weather currents and the conducting Earth. We suggest that it is needed to change the conventional picture of global electric circuit and the contribution of gigantic jets and possibly red sprites should be included. It is observed that a gigantic jet can release energy of the order of 1 MJ [64] which may be hazardous to the aircraft flying in the near space. Elves produces the perturbations in the ionospheres and enhances the free electron density so it is suggested that to model the atmospheric chemical reactions over the elves heated region a proper inclusion of effects of elves is required. In addition, the combined energy released by the TLEs will cause violent chemical reaction and may impact significantly on the physical and chemical environment in their region of occurrence so a detailed study is required in this direction also. It is suggested that TGFs which are generally considered to be associated with thunderstorms and tropospheric lightning activity may also be associated with TLEs. The underlying mechanism by which lightning discharges are associated with TGFs is still not clear.

However, it should be noted that most of the previous theoretical work on TLEs is based on numerical simulation which cannot provide us analytical results. A complete analytical work is required to study them properly. Physical mechanism of delayed sprites is unclear because we do not have a separate formula related to sprite current and time lag to the parameters of causative lightning. Some more questions which are still to be discovered, like what are the conditions of the atmosphere which are responsible for the different shapes of sprites? In spite of the various models suggested by different authors, sprite morphology (especially their fine spatial structure and clustering) is still not fully understood. What is the exact relationship between the behavior of parent lightning and various shapes of the sprites? How the parent lightning affect the distribution, the brightness, and the length of various type of sprites. What is the ionization level of the atmosphere in the regions where TLEs occur? Why gigantic jets have tree like shape? How TLEs affect the stratospheric ozone level? A detailed mechanism of the production of TGFs and its association with electrical activity in Earth ${ }^{\text {ee }}$ atmosphere should also be investigated. However, the most accepted hypothesis suggests that the thunderstorm acts as a particle accelerator and free electrons can be accelerated to relativistic energy in its electric fields and produce $\mathrm{X}$-rays and $\gamma$-rays via a bremsstrahlung process, against atoms and nuclei in the atmosphere [91]. However, the production mechanism of these events is still a matter of debate. There are a lot of such problems which should be properly solved in near future to know about these electrical discharges in details.

\section{Acknowledgements}

The authors are highly thankful to the Government of Uttar Pradesh, India. The authors are also thankful to anonymous reviewers for their critical comments and valuable suggestions which helped in improving the value of this paper. 


\section{References}

[1] M. A. Uman, The lightning discharge, San Diego: Academic Press, pp. 1-377, 1987.

[2] V. A. Rakov, Lightning phenomenology and parameters important for lightning protection, IX International Symposium on Lightning Protection, Foz do Iguacu, Brazil, 26 $6^{\text {th }}-30^{\text {th }}$ November, 2007.

[3] A. B. Chen, C. L. Kuo, Y. J. Lee, H. T. Su, R. R. Hsu, J. L. Chern, H. U. Frey, B. M. Stephen, Y. Takahashi, H. Fukunishi, Y. S. Chang, T. Y. Liu, L. C. Li, Global distributions and occurrence rates of transient luminous events, Journal of Geophysical Research, 113, A08306 2008.

[4] M. Azadifar, F. Rachidi, M. Rubinstein, V. A. Rakov, M. Paolone, D. Pavanello, Bipolar lightning flashes observed at the Säntis tower, 33 ${ }^{\text {rd }}$ International Conference on Lightning Protection, Estoril, Portugal, 25-30 September, 2016.

[5] V. A. Rakov, The physics of lightning, Surv Geophys, 34, 701-729, 2012.

[6] V. Jayakumar, V. A. Rakov, M. Miki, M. A. Uman, G. H. Schnetzer, K. J. Rambo, Estimation of input energy in rocket-triggered lightning, Geophysical Research Letters, 33, L05702, 2006.

[7] T. Enoto, Y. Wada, Y. Furuta, K. Nakazawa, T. Yuasa, K. Okuda, K. Makishima, M. Sato, Y. Sato, T. Nakano, D. Umemoto, H. Tsuchiya, Photonuclear reactions triggered by lightning discharge, Nature, 551, 481-484 2017.

[8] T. Torii, M. Takeishi, T. Hosono, Observation of gamma-ray dose increase associated with winter thunderstorms and lightning activity, Journal of Geophysical Research, 107, 4324, 2002.

[9] J. R. Dwyer, D. M. Smith, B. J. Hazelton, B. W. Grefenstette, N. A. Kelley, A. W. Lowell, M. M. Schaal, H. K. Rassoul, Positron clouds within thunderstorms, Journal of Plasma Physics, 81, 475810405, 2015.

[10] G. J. Fishman, P. N. Bhat, R. Mallozzi, J. M. Horack, T. Koshut, C. Kouveliotou, G. N. Pendleton, C. A. Meegan, R. B. Wilson, W. S. Paciesas, S. J. Goodman, H. J. Christian, Dicovery of intense gamma-ray flashes of atmospheric origin, Science, 264, 1313-1316, 1994.

[11]D. Wang, N. Takagi, T. Watanabe, V. A. Rakov, M. A. Uman, K. J. Rambo, M. V. Stapleton, A comparison of channel-base currents and optical signals for rockettriggered lightning strokes, Atmospheric Research, 76, 412-422, 2005

[12]D. D. Sentman, and E. M. Wescott, Video observations of upper atmospheric optical flashes recorded from an aircraft, Geophysical Research Letters, 20, 2857, 1993.

[13]R. J.-S. Chern, S.-F. Lin, A.-M. Wu, Ten-year transient luminous events and Earth observations of FORMOSAT-2, Acta Astronautica, 112, 37-47, 2015.
[14]T. Mackenzie and H. Toynbee, Meteorological Phenomena, Nature, 33, 26, 1886.

[15]R. C. Franz, J. Nemzek, J. R. Winckler, Television image of a large upward electrical discharge above a thunderstorm system, Science, 249, 48-51, 1990.

[16]C. L. Kuo, E. Williams, J. Bor, Y. H. Lin, L. J. Lee, S. M. Huang, J. K. Chou, A. B. Chen, H. T. Su, R. R. Hsu, G. Satori, H. U. Frey, S. B. Mende, Y. Takahashi, L. C. Lee, Ionization emissions associated with $\mathrm{N}_{2}{ }^{+} 1 \mathrm{~N}$ band in halos without visible sprite streamers, Journal of Geophysical Research: Space Physics, 118, 5317-5326, 2013.

[17]V. Cooray, Charge generation in thunderclouds and different forms of lightning flashes, In: An introduction to lightning, Springer, Dordrechet, 2015.

[18]V. A. Rakov and M. A. Uman, Lightning: Physics and effects, Cambridge University Press, 2003.

[19]A. Chilingarian, S. Chilingaryan, T. Karapetyan, Y. K. Kozliner, G. Hovsepyan, D. Pokhsraryan, S. Soghomonyan, On the initiation of lightning in thunderclouds, Scientific Reports, 1-10. 7: 1371, doi:10.1038/s41598-017-01288-0, 2017.

[20]D. Wang and N. Takagi, A downward positive leader that radiated optical pulses like a negative stepped leader, Journal of Geophysical Research, 116, D10205, 2011.

[21]M. Buguet, P. Lalande, P. Blanchet, S. Pedeboy, P. Barneoud, P. Laroche, Observation of Cloud-to-Ground Lightning Channels with High-Speed Video Camera, $X V$ International Conference on Atmospheric Electricity, Norman, Oklahoma, U.S.A., 15-20 June 2014.

[22]D. M. Fuquay, Positive cloud-to-ground lightning in summer thunderstorms, Journal of Geophysical Research, 87 (C9), 7131-7140, 1982.

[23]W. H. Beasley, Positive cloud-to-ground lightning observations, Journal of Geophysical Research, 90 (D4), 6131-6138, 1985.

[24] A. Nag, V. A. Rakov, Positive lightning: An overview, new observations, and inferences, Journal of Geophysical Research, 117, D08109, 2012.

[25]V. Cooray, On the upper limit of peak current in return strokes of lightning flashes, $X$ international Symposium on Lightning Protection, Curitiba, Brazil, 167-172, 9-13 November 2009.

[26]R. E. Orville, Spectrum of the lightning dart leader, Journal of the Atmospheric Sciences, 32, 1829-1837, 1975.

[27] A. Nag, V. A. Rakov, W. Schulz, M. M. F. Saba, R. Thottappillil, C. J. Biagi, A. O. Filho, A. Kafri, N. Theethayi, T. Gotschl, First versus subsequent returnstroke current and field peaks in negative cloud-toground lightning discharges, Journal of Geophysical Research, 113, D19112, 2008.

[28]M. M. F. Saba, M. G. Ballarotti, O. Pinto Jr., Negative cloud-to-ground lightning properties from high-speed 
video observations, Journal of Geophysical Research, 111, D03101, 2006.

[29] W. A. Lyons, Sprite observations above the U.S. High Plains in relation to their parent thunderstorm systems, Journal of Geophysical Research, 101, 29641, 1996.

[30] D. D. Sentman, E. M. Wescott, D. L. Osborne, D. L. Hampton, M. J. Heavner, Preliminary results from the sprites94 aircraft campaign:1, Red sprites, Geophysical Research Letters, 22, 1205-1208, 1995.

[31] Y. Jing, Q. XiuShu, Z. GuangShu, Z. Yang, Z. Tong, Red sprites over thunderstorms in the coast of Shandong Province, China, Chinese Science Bulletin, 53, 10791086, 2008.

[32]E. R. Williams, Sprites, elves, and glow discharges tubes, Physics Today, 41-47, November 2001.

[33] M. G. McHarg, H. C. Stenbaek-Nielsen, T. Kammae, Observations of streamer formation in sprites, Geophysical Research Letters, 34, L06804, 2007.

[34]M. Stanley, P. Krehbiel, M. Brook, C. Moore, W. Rison, B. Abrahams, High speed video of initial sprite development, Geophysical Research Letters, 26, 32013204, 1999.

[35] K. M. Peng, R. R. Hsu, H.-T. Su, A. Chen, J.-K.Chou, S.-C. Chang, Y.-J. Wu, C.-L. Hung, L.-C. Yang, S.-H. Tsai, Transient luminous event coordinated observations using FORMOSAT-2 satellite and Taiwan sprites campaign, Terrestrial, Atmospheric and Oceanic Sciences. 28, 597-608, 2017.

[36] D. J. Boccippio, E. R. Williams, S. J. Heckman, W. A. Lyons, I. T. Baker, R. Boldi, Sprites, ELF transients, and positive ground strokes, Science, 269, 1088, 1995.

[37] J. R. Winckler, W. A. Lyons, T. E. Nelson, R. J. Nemzek, New high-resolution ground-based studies of sprites, Journal of Geophysical Research, 101, 69977004, 1996.

[38] S. A. Cummer, U. S. Inan, T.F. Bell, C. P. BarringtonLeigh, ELF radiation produced by electrical currents in sprites, Geophysical Research Letters, 25, 1281-1284 1998.

[39] C. L. da Silva, V. P. Pasko, Heating of mesospheric air by sprites and its implications for production of infrasonic acoustic waves, $X V$ International Conference on Atmospheric Electricity, Norman, Oklahoma, U.S.A., 15-20 June 2014.

[40] W. Hu, S. A. Cummer, W. A. Lyons, T. E. Nelson, Lightning charge moment changes for the initiation of sprites, Geophysical Research Letters, 29, 1279, doi:10.1029/2001GL014593, 2002.

[41]S. A. Cummer, Measurements of lightning parameters from remote electromagnetic fields, Proceedings of the NATO Advanced Study Institute on "Sprites, Elves and Intense Lightning Discharges”, 191-210, 2006.

[42] D. L. Hampton, M. J. Heavner, E. M. Wescott, D. D. Sentman, Optical spectral characteristics of sprites, Geophysical Research Letters, 23, 89-92, 1996.
[43] G. Milikh, J. A. Valdivia, K. Papadopoulos, Spectrum of red sprites. Journal of Atmospheric and SolarTerrestrial Physics, 60, 907-915, 1998.

[44] V. P. Pasko, U. S. Inan, Y. N. Taranenko, T. F. Bell, Heating, ionization and upward discharges in the mesosphere due to intense quasi-electrostatic thunderclouds fields, Geophysical Research Letters, 22, 365-368, 1995.

[45]T. F. Bell, V. P. Pasko, U. S. Inan, Runaway electrons as a source of red sprites in the mesosphere, Geophysical Research Letters, 22, 2127-2130, 1995.

[46] V. Yukhimuk, R. A. Roussel -Dupré, E. M. D. Symbalisty, Optical Characteristics of red sprites produced by runaway air breakdown, Journal of Geophysical Research, 103, 11473-11482, 1998.

[47]C. T. R. Wilson, The electric field of a thundercloud and some of its effects, Proc. Phys. Soc. London, 37, 32D-37D, 1925.

[48] V. P. Pasko, U. S. Inan, T. F. Bell, Y. N. Taranenko, Sprites produced by quasi-electrostatic heating and ionization in the lower ionosphere, Journal of Geophysical Research, 102 (3), 4529-4561, 1997.

[49] Y. P. Raizer, G. M. Milikh, M. N. Shneider, and S. V. Novakovski, Long streamers in the upper atmosphere above thundercloud, Journal of Physics D: Applied Physics, 31, 3255-3264, 1998.

[50] V. P. Pasko, Red sprite discharges in the atmosphere at high altitude: the molecular physics and the similarity with laboratory discharges, Plasma sources science and technology, 16, S13-S29, 2007.

[51]A. V. Gurevich, G. A. Milikh, R. Roussel-Dupre , Runaway electron mechanism of air breakdown and preconditioning during a thunderstorm, Phys. Lett. A, 165, 463-468, 1992.

[52]H. A. Bethe, Zur Theorie des Durchgangs schneller Korpuskularstrahlen durch Materie, Annalen der Physik, 397, 325-400, 1930.

[53] V. V. Surkov and M. Hayakawa, Underlying mechanism of transients luminous events: a review, Annales Geophysicae, 30, 1185-1212, 2012.

[54]A. V. Gurevich, K. P. Zybin, Runaway breakdown and electric discharges in thunderstorm, Phys.-Uspekhi., 44, 1119-1140, 2001

[55]E. M. Wescott, D. Sentman, D. Osborne, D. Hampton, M. Heavner, Preliminary results from the Sprites94 aircraft campaign:2. Blue jets, Geophysical Research Letters, 22,1209-1212, 1995.

[56] W. A. Lyons, T. E. Nelson, R.A. Armstrong, V. P. Pasko, M. Stanley, Upward electrical discharges from the tops of thunderstorms, Bull. Amer. Meteor. Soc., 84, 445-454, 2003b.

[57]V. P. Pasko, Blue jets and gigantic jets: transient luminous events between thunderstorm tops and the lower ionosphere, Plasma Physics and Controlled Fusion, 50, 124050, 2008. 
[58] V. P. Pasko, J. George, Three dimensional modeling of blue jets and blue starters, Journal of Geophysical Research, 107, 1458, 2002.

[59] E. M. Wescott, D. D. Sentman, M. J. Heavner, D. L. Hampton, O. H. Vaughan, Blue jets: their relationship to lightning and very large hail fall, and their physical mechanisms for their production, Journal of Atmospheric and Solar-Terrestrial Physics 60, 713724, 1998.

[60] V. P. Pasko, M. A. Stanley, J. D. Mathews, U. S. Inan, T. G. Wood, Electrical discharge from a thundercloud top to the lower ionosphere, Nature, 416, 152-154, 2002.

[61]S. Soula, O.V. D. Velde, J. Montanya, P. Huet, C. Barthe, J. Bor, Gigantic jets produced by an isolated tropical thunderstorm near Réunion Island, Journal of Geophysical Research, 116, D19103, 2011.

[62] J. K. Chou, C. L. Kuo, L. Y. Tsai, A. B. Chen, H. T. Su, R. R. Hsu, S. A. Cummer, J. Li, H. U. Frey, S. B. Mende, Y. Takahashi, L. C. Lee, Gigantic jets with negative and positive polarity streamers, Journal of Geophysical Research, 115, A00E45, 2010.

[63] S. A. Cummer, J. Li, F. Han, G. Lu, N. Jaugey, W. A. Lyons, T. E. Nelson, Quantification of the troposphere-to-ionosphere charge transfer in a gigantic jet, Nature Geoscience, 2, 617-620, 2009.

[64]H. T. Su, R. R. Hsu, A. B. Chen, Y. C. Wang, W. S. Hsiao, W. C. Lai, L. C. Lee, M. Sato, H. Fukunishi, Gigantic jets between a thundercloud and the ionosphere, Nature, 423, 974-976, 2003.

[65] O. A. van der Velde, J. Bór, J. Li, S. A. Cummer, E. Arnone, F. Zanotti, M. Füllekrug, C. Haldoupis, S. N. Amor, T. Farges, Multi-instrumental observations of a positive gigantic jet produced by a winter thunderstorm in Europe, Journal of Geophysical Research, 115, D24301, 2010.

[66] G. M. Milikh, M. N. Shneider, M. S. Mokrov, Model of blue jet formation and propagation in the non uniform atmosphere, Journal of Geophysical Research: Space Physics, 119, 5821-5829, 2014.

[67] V. P. Pasko, U. S. Inan, T. F. Bell, Blue jets produced by quasi-electrostatic pre-discharge thundercloud fields, Geophysical Research Letters, 23, 301-304, 1996.

[68] A. I. Sukhorukov, E. V. Mishin, P. Stubbe, M. J. Rycroft, On blue jet dynamics, Geophysical Research Letters, 23, 1625-1628, 1996.

[69] Y. P. Raizer, G. M. Milikh, M. N. Shneider, Leaderstreamer nature of blue jets, Journal of Atmospheric and Solar-Terrestrial Physics, 69, 925-928, 2007.

[70]D. Singh, R. P. Singh, S. Kumar, T. Dharmraj, A. K. Singh, A. K. Singh, M. N. Patil, S. Singh, Lightning and middle atmospheric discharges in the atmosphere, Journal of Atmospheric and Solar-Terrestrial Physics, 134, 78-101, 2015.

[71] G. Lu, Transient electric field at high altitudes due to lightning: Possible role of induction field in the formation of elves, Journal of Geophysical Research, 111, D02103, 2006.

[72]C. P. Barrington-Leigh, U. S. Inan, Elves triggered by positive and negative lightning discharges, Geophysical Research Letters, 26, 683-686, 1999.

[73]R. T. Newsome, U. S. Inan, Free-running ground-based photometric array imaging of transient luminous events, Journal of Geophysical Research, 115, A00E41, 2010.

[74]Z. Cheng, S. A. Cummer, H.-T. Su, R.-R. Hsu, Broadband very low frequency measurement of $D$ region ionospheric perturbations caused by lightning electromagnetic pulses, Journal of Geophysical Research, 112, A06318, 2007.

[75] U. S. Inan, T. F. Bell, J. V. Ridriguez, Heating and ionization of the lower ionosphere by lightning, Geophysical Research Letters, 18, 705-708, 1991.

[76] Y. N. Taranenko, U. S. Inan, T. F. Bell, The interaction with the lower ionosphere of electromagnetic pulses from lightning: Excitation of optical emissions, Geophysical Research Letters, 20, 2675, 1993.

[77]U. S. Inan, W. A. Sampson, Y. N. Taranenko, Spacetime structure of optical flashes and ionization changes produced by lightning-EMP, Geophysical Research Letters, 23, 133-136, 1996.

[78] C. P. Barrington-Leigh, U. S. Inan, M. Stanley, F.G. Smith, Identification of sprites and elves with intensified video and broadband array photometry, Journal of Geophysical Research, 106 (A2), 1741-1750, 2001.

[79] Y. Hobara, N. Iwasaki, T. Hayashida, M. Hayakawa, K. Ohta, H. Fukunishi, Interrelation between ELF transients and ionospheric disturbances in association with sprites and elves, Geophysical Research Letters, 28, 935-938, 2001.

[80]C. J. Rodger, Red sprites, upwards lightning, and VLF perturbations, Reviews of Geophysics, 37, 317-336, 1999.

[81] V. P. Pasko, Electric jets, Nature, 423, 927-929, 2003.

[82]E. Williams, E. Downes, R. Boldi, W. Lyons, S. Heckman, Polarity asymmetry of sprite-producing lightning : A Paradox? Radio Science, 42, RS2S17, 2007.

[83]H. U. Frey, S. B. Mende, S. A. Cummer, J. Li, T. Adachi, H. Fukunishi, Y. Takahashi, A. B. Chen, R.R. Hsu, H.-T. Su, Y.-S. Cheng, Halos are generated by negative cloud-to-ground lightning, Geophysical Research Letters, 34, L18801, 2007.

[84]R. Miyasato, M. J. Taylor, H. Fukunishi, H. C. Stenbaek-Nielsen, Statistical characteristics of sprite halo events using coincident photometric and imaging data. Geophysical Research Letters, 29, 2033, 2002.

[85] D. L. Finny, R. M. Doherty, O. Wild, P. J. Young, A Butler, Response of lightning $\mathrm{NO}_{\mathrm{x}}$ emissions and ozone production to climate change: Insights from the atmospheric chemistry and climate model 
intercomparison project, Geophysical Research Letters, 43, 5492-5500, 2016.

[86]D. M. Romps, J. T. Seeley, D. Vollaro, J. Molinari, Projected increase in lightning strikes in the United States due to global warming, Science, 346, 851-854, 2014.

[87] C.-F. Enell, E. Arnone, T. Adachi, O. Chanrion, P. T. Verronen, A. Seppala, T. Neubert, T. Ulich, E. Turunen, Y. Takahashi, R.-R. Hsu, Parameterisation of the chemical effect of sprites in the middle atmosphere, Annales Geophysicae, 26, 13-27, 2008.

[88]W. O. Schumann, "Uber die Strahlunglosen Eingeschwigungen einer leitenden Kugel die von Luftschift und einer Ionosparenhulle ungeben ist," Zeitschrift Naturforschung, 7a, 140-154, 1952.

[89] M. K. Paras and J. Rai, Propagation of ELF radiation from RS-LC System and Red Sprites in EarthIonosphere waveguide, Advanced Electromagnetics, 1, 96-102, 2012.

[90]D. R. Shklyar, Energy transfer from lower energy to higher-energy electrons mediated by whistler waves in the radiation belts, Journal of Geophysical Research: Space Physic, 122, 640-655, 2017.

[91] A. Ursi, M. Marisaldi, M. Tavani, P. San`o, D. Casella, S. Dietrich, Detection of terrestrial gamma-ray flashes with the AGILE satellite, IOP Conf. Series: Journal of Physics: Conf. Series 841, 012029, 2017.
[92] G. J. Fishman, P. N. Bhat, R. Mallozzi, J. M. Horack, T. Koshut, C. Kouveliotou, G. N. Pendleton, C. A. Meegan, R. B. Wilson, W. S. Paciesas, S. J. Goodman, H. J. Christian, Discovery of intense gamma-ray flashes of atmospheric origin, Science, 264, 1313-1316, 1994.

[93] V. V. Bogomolov, M. I. Panasyuk, S. I. Svertilov, A. V. Bogomolov, G. K. Garipov, A. F. Iyudin, P. A. Klimov, S. I. Klimov, T. M. Mishieva, P. Yu. Minaev, V. S. Morozenko, O. V. Morozov, A. S. Posanenko, A. V. Prokhorov, H. Rotkel, Observation of terrestrial gamma-ray flashes in the RELEC space experiment on the Vernov satellite, Cosmic Research, 55 (3), 159-168, 2017.

[94] N. A. Kelley, D. M. Smith, J. R. Dwyer, M. Splitt, S. Lazarus, F. Martinez-McKinney, B. Hazelton, B. Grefenstette, A. Lowell, H. K. Rassoul, Relativistic electron avalanches as a thunderstorm discharge competing with lightning, Nature communications, DOI: 10.1038/ncomms8845, 2015.

[95] N. Y. Liu., V. P. Pasko, K. Adams, H. C. StenbaekNielsen, M. G. McHarg, Comparison of acceleration, expansion, and brightness of sprite streamers obtained from modeling and high-speed video observations, Journal of Geophysical Research, 114, A00E03, 2009. 